\title{
Práticas de avaliação de dois professores universitários: pesquisa utilizando observações e narrativas de atividades das aulas
}

\section{Assessment practices of two university professors: a study using observations and narratives built on class activities}

Domingos Fernandes ${ }^{1}$

\begin{abstract}
RESUMO
O propósito deste estudo era compreender práticas de ensino e avaliação de dois docentes universitários de Artes e Humanidades, tendo-se analisado: a) a organização do ensino e as dinâmicas de sala de aula; b) as tarefas de ensino e avaliação utilizadas e papéis de alunos e docentes; c) o feedback; e d) as utilizações da avaliação. Os dados foram coletados através de observações e entrevistas aos professores e aos alunos. As narrativas mostraram que os docentes utilizaram práticas de ensino e avaliação diferentes ainda que partilhassem perspetivas pedagógicas semelhantes. A pesquisa permitiu concluir que aulas estruturadas com propósitos claros e bem definidas; dinâmicas de ensino e avaliação diversificadas; utilização de tarefas criteriosamente selecionadas; participação ativa dos alunos nos processos de aprendizagem e avaliação; distribuição sistemática de feedback de qualidade; utilização da avaliação formativa; e utilização de processos de auto e heteroavaliação estão associadas a melhores aprendizagens, de acordo com as opiniões dos alunos e dos docentes. A pesquisa permitiu ainda elaborar reflexões relacionadas com a natureza das tarefas, a participação dos alunos, o feedback e a qualidade das aprendizagens.
\end{abstract}

Palavras-chave: práticas de ensino; práticas de avaliação; avaliação formativa; ensino superior.

DOI: $10.1590 / 0104-4060.41488$

1 Universidade de Lisboa. Instituto de Educação da Universidade de Lisboa. Lisboa, Portugal. Alameda da Universidade 1649-013.E-mail: dfernandes@ie.ul.pt 


\begin{abstract}
The main purpose of this study was to understand teaching and assessment practices of two university professors of Arts and Humanities. Thus, the following pedagogical aspects were analyzed: a) teaching organization and classroom dynamics; b) teaching and assessment tasks as well as professors and students' roles; c) feedback; and d) utilization of assessments. Data were collected through classroom observations and both professors and students' interviews. Narratives showed that although professors shared similar pedagogical perspectives, they made use of different teaching and assessment practices. This study allowed one to conclude that well defined structured classes with clear purposes; diversified teaching and assessment dynamics; utilization of carefully selected tasks; students' active participation in the learning and assessment processes; systematic distribution of high quality feedback; utilization of formative assessment; and utilization of self and combined modes of assessment are closely related to better learning, according to both professors and students' accounts. Besides, this research enabled one to come up with some reflections on the tasks nature, students' participation, feedback and quality of learning.
\end{abstract}

Keywords: teaching practices; assessment practices; formative assessment; higher education.

\title{
Introdução
}

A pesquisa que se apresenta e discute neste artigo enquadra-se num projeto mais amplo, financiado pela Fundação para a Ciência e Tecnologia (FCT) de Portugal (PTDC/CPE-CED/114318/2009), envolvendo 36 investigadores de sete universidades (quatro portuguesas e três brasileiras) e que decorre entre Abril de 2011 e Abril de 2014. O seu principal propósito era descrever, analisar e interpretar práticas de ensino e de avaliação dos docentes e aspetos relacionados com as aprendizagens dos alunos no contexto de unidades curriculares de quatro grandes áreas do conhecimento: Ciências Sociais, Artes e Humanidades, Ciências da Saúde e Ciências e Tecnologias.

O projeto foi desenvolvido de acordo com cada uma das seguintes fases, fortemente relacionadas entre si: a) Fase Teórica e Conceitual, em que se construiu um referencial teórico a partir de uma análise abrangente e profunda da literatura internacional relevante nos domínios do ensino, da avaliação e das aprendizagens em contextos do ensino superior; b) Fase da Análise Documen- 
tal, cujo principal propósito foi analisar as principais orientações pedagógicas constantes nos regulamentos e em outros artefatos institucionais produzidos e utilizados em cada uma das universidades participantes; c) Fase do Estudo Extensivo, em que se concebeu e administrou um questionário a professores e alunos tendo em vista estudar as suas perceções relativamente a uma variedade de dimensões relacionadas com o ensino, a avaliação e as aprendizagens; d) Fase do Estudo Intensivo, na qual se observaram aulas de unidades curriculares de cada um dos domínios do conhecimento acima indicados e se entrevistaram formal e informalmente os respetivos professores e alunos; e e) Fase da Interação Social e da Reflexão, cujo principal propósito era promover uma interação próxima e deliberada com uma diversidade de intervenientes para suscitar reflexões que, de algum modo, pudessem contribuir para analisar e interpretar os dados obtidos nas fases anteriores.

Tendo em conta os propósitos e a natureza da pesquisa, uma parte bastante significativa dos dados foi obtida através das observações e entrevistas realizadas na Fase Intensiva. Em cada universidade foram observadas 20 horas de aulas em cada uma das duas unidades curriculares de cada um dos domínios do conhecimento já referidos. Nestas condições, observaram-se cerca de 1.960 horas de aulas em todos os domínios. Ou seja, 280 horas de aulas em cada um, tendo sido entrevistados 56 professores e 140 alunos. Em cada universidade e para cada unidade curricular, estão a ser construídas narrativas, resultantes das observações e das entrevistas, para cada domínio do conhecimento. Assim, teremos, numa primeira fase e para cada uma das universidades, 2 narrativas para as Ciências Sociais, 2 para as Artes e Humanidades e assim sucessivamente. Os procedimentos de integração e de transformação dos dados foram organizados de forma a que, para cada domínio do conhecimento, se possa obter uma só narrativa por universidade e, consequentemente, haverá 7 narrativas por cada domínio para o total das universidades. Além disso, o questionário administrado na Fase Extensiva envolveu centenas de docentes e milhares de alunos. Trata-se de uma significativa massa de dados qualitativos e quantitativos cuja integração e transformação já está a decorrer em cada uma das referidas instituições.

A pesquisa que se apresenta neste artigo foi exclusivamente baseada na observação de aulas de duas unidades curriculares, aqui designadas por Desenho e História da Arte, da área das Artes e Humanidades de uma universidade e nas entrevistas realizadas aos seus dois professores e a dois grupos de estudantes (um com quatro e outro com cinco elementos). Nestas condições, trata-se de uma parte significativamente reduzida do trabalho de pesquisa que se vem realizando no âmbito do projeto acima referido. 


\section{Enquadramento conceptual}

A produção de conhecimento relacionada com questões de natureza pedagógica está associada a necessidades expressas pelos dirigentes políticos e económicos para melhorar significativamente a qualidade do que se ensina e do que se aprende nas universidades. No contexto do espaço europeu, o chamado processo de Bolonha consubstancia um conjunto de ideias subscritas em 1999 por todos os países da união que aponta claramente para a necessidade de transformar e melhorar os processos pedagógicos nas instituições do ensino superior. Obviamente que este movimento pedagógico, que vem atravessando o ensino superior gerando muitas pesquisas e reflexões sobre uma diversidade de temas, tais como a organização e desenvolvimento do ensino, a seleção de tarefas e os processos de avaliação, está intrinsecamente associado aos contextos sociais, políticos e às tensões de toda a ordem, inclusive ideológicas, que presentemente se vivem na Europa e no mundo. As políticas públicas relativas ao ensino superior que se têm desenvolvido nos últimos anos apresentam três caraterísticas bem definidas: a) aproximação às lógicas de mercado (e.g. consultorias, venda de serviços, captação de fundos); b) desenvolvimento de processos de fusão interinstitucional e de internacionalização; e c) concretização de uma diversidade de reconfigurações institucionais (e.g. mudanças nas formas de trabalho académico, avaliações para legitimar as instituições, índices de citação que outorgam prestígio profissional). Consequentemente, há uma diversidade de fenómenos mais ou menos recentes no ensino superior (e.g. autonomia regulada pela avaliação, regulação do trabalho académico, reorganização das atividades de investigação, transnacionalização) que afetam necessariamente as identidades, os valores e as formas de agir e de interagir dos docentes universitários. Em última análise afectam as formas como eles ensinam e avaliam para que os seus alunos aprendam o que são supostos aprender.

Escudero (2012), ao referir-se ao Espaço Europeu de Educação Superior (EEES), mais de 10 anos passados sobre o acordo de Bolonha, considera que, apesar da multiplicidade de relatórios, que nos dão conta de grandes tendências, e de pesquisas realizadas no domínio das práticas organizacionais e pedagógicas, conhece-se pouco o seu real impacto numa variedade de aspetos, tais como os processos e relações pedagógicas, as aprendizagens dos alunos e as ações dos professores. Mas, na opinião deste investigador, uma coisa parece certa: a fonte da contestação às "reformas" decorrentes do processo de Bolonha está essencialmente nas perspetivas técnicas, burocráticas e "descaradamente mercantis" que as influenciam e não nas mudanças pedagógicas que eram e continuam a ser consideradas desejáveis e necessárias. Efetivamente a "embalagem geren- 
cialista e mercantil da reforma" é objeto de controvérsia e, com ela, o modelo de universidade, de docência e de formação dos alunos que lhe está subjacente.

No referido trabalho, Escudero (2012) procura conceitualizar a inovação docente assim como a melhoria, a transformação ou a mudança, tendo em conta dois eixos fundamentais. No primeiro eixo, por exemplo, pode considerar-se a melhoria da docência em geral como uma questão meramente técnica, reflexiva ou como um compromisso crítico e militante de transformação. O segundo eixo tem a ver com a abrangência e com os atores implicados e, assim, pode considerar-se que a melhoria pretendida pode desenvolver-se ao nível individual, institucional ou social. No Quadro 1, sintetiza-se o marco conceitual utilizado por aquele autor para discutir questões relacionadas com a melhoria/inovação/ mudança.

Esse referencial teórico que "arruma" três abordagens à inovação, à mudança e/ou à melhoria da docência, segundo três níveis ou dimensões, de acordo com o contexto em que os atores estão inseridos, permite situar o docente na sala de aula onde, como se sabe, os seus conhecimentos, as suas conceções e as suas ações podem fazer toda a diferença ainda que os níveis macro e meso possam não ser propriamente os mais favoráveis à mudança. Na verdade, uma das características interessantes deste enquadramento é precisamente a sua flexibilidade, pois as células do quadro não são propriamente compartimentos estanques nem necessariamente interdependentes. Ou seja, pode haver situações em que as políticas sejam orientadas para a estandardização e para a regulação, mas a resistência das práticas institucionais e individuais pode criar condições para a disseminação de inovações nestes níveis de ação.

\section{QUADRO 1 - ENQUADRAMENTO CONCEITUAL PARA A INOVAÇÃO E/OU MELHORIA E/OU MUDANÇA DOCENTE}

\begin{tabular}{|c|l|l|l|}
\hline $\begin{array}{c}\text { Individual } \\
\text { (Micro) }\end{array}$ & $\begin{array}{l}\text { Técnica } \\
\begin{array}{l}\text { Inovações "à prova } \\
\text { dos professores" ou } \\
\text { "independentes dos } \\
\text { professores". }\end{array}\end{array}$ & $\begin{array}{l}\text { Reflexiva } \\
\text { Professores reflexivos, } \\
\text { investigadores e árbitros } \\
\text { das reformas. }\end{array}$ & $\begin{array}{l}\text { Professores críticos, } \\
\text { militantes, resistentes, } \\
\text { transformadores. }\end{array}$ \\
\hline $\begin{array}{c}\text { Institucional } \\
\text { (Meso) }\end{array}$ & $\begin{array}{l}\text { Inovações } \\
\text { estandardizadas e } \\
\text { fortemente reguladas. }\end{array}$ & $\begin{array}{l}\text { As instituições } \\
\text { escolares são a base } \\
\text { para a autonomia e o } \\
\text { desenvolvimento. }\end{array}$ & $\begin{array}{l}\text { Autonomia, } \\
\text { responsabilidade e ética } \\
\text { institucional a serviço da } \\
\text { justiça e da equidade. }\end{array}$ \\
\hline $\begin{array}{c}\text { Social } \\
\text { (Macro) }\end{array}$ & $\begin{array}{l}\text { Inovações dirigidas e } \\
\text { controladas pelas forças } \\
\text { sociais e económicas } \\
\text { hegemónicas. }\end{array}$ & $\begin{array}{l}\text { Políticas de centralização } \\
\text { de alguns elementos } \\
\text { e descentralização de } \\
\text { outros. }\end{array}$ & $\begin{array}{l}\text { Políticas sociais e } \\
\text { educativas para a } \\
\text { democracia, a justiça e a } \\
\text { equidade. }\end{array}$ \\
\hline
\end{tabular}

FONTE: Adaptado de ESCUDERO (2012, p. 7). 
A pesquisa que aqui se apresenta e discute é, de acordo com o enquadramento sugerido por Escudero (2012), do âmbito micro, pois foi delineada para conhecer e compreender práticas docentes (sobretudo individuais) de ensino e de avaliação no contexto concreto das suas salas de aula. Na verdade, e de acordo com vários autores (e.g. BLACK; WILIAM, 1998, 2006; FALCHICOV, 2005; YORKE, 2003), as salas de aula podem ser os espaços e contextos decisivos para que se possam pôr em prática mudanças e inovações que melhorem substancialmente o que, e como, os alunos aprendem. Talvez por isso mesmo, nunca, como nos últimos anos, se prestou tanta atenção ao papel que os docentes universitários podem desempenhar na organização e desenvolvimento do ensino e da avaliação para melhorar as aprendizagens dos alunos. Neste sentido, a docência tem que ser encarada como um processo de criação e desenvolvimento de conhecimento $\mathrm{e}$, consequentemente, tem que ser estudada para que possa ser mais conhecida e mais compreendida em todas as suas dimensões. Este será porventura o caminho que nos permitirá evitar a ignorância, a trivialidade e a irrelevância quando se trata de discutir questões pedagógicas que estão diretamente relacionadas com as aprendizagens dos alunos.

A pesquisa realizada, quer ao nível do ensino superior quer ao nível do ensino não superior, tem evidenciado que, em geral, há uma significativa relação entre as práticas de ensino e de avaliação e as aprendizagens dos alunos. Mais concretamente, sabe-se que todos os alunos aprendem mais e, sobretudo, melhor quando a avaliação formativa faz parte integrante da organização e desenvolvimento do ensino. (e.g. BLACK; WILIAM, 1998; FERNANDES, 2008; GARDNER, 2006). Apesar destes resultados, a verdade é que a investigação realizada em contextos de ensino superior tem sugerido que as práticas de ensino são essencialmente baseadas na transmissão de conhecimentos que são exclusivamente avaliados através de testes e/ou exames finais. (e.g. BIGGS, 2006; YORKE, 2003).

Fernandes e Fialho (2012) desenvolveram uma síntese interpretativa de literatura internacional publicada num período de 10 anos (2000-2009), em que os pesquisadores tiveram como propósito principal estudar práticas de ensino e de avaliação de docentes universitários em contextos reais de sala de aula. Todas as investigações analisadas relatavam intervenções que tinham sido deliberadamente pensadas e planeadas para introduzir inovações e melhorias nas formas de organizar o ensino e a avaliação. Ficou então claramente evidenciado que é possível ensinar e avaliar para apoiar a melhoria das aprendizagens. De modo geral, puderam observar-se situações tais como: a) os docentes estruturavam as aulas e incutiam-lhes dinâmicas diversificadas de avaliação e de ensino; b) as tarefas eram diversificadas e cuidadosamente selecionadas; c) os alunos participavam mais ou menos ativamente nas atividades das aulas; d) a interação 
social era apoiada por feedback sistemático e de qualidade; e e) a avaliação de natureza formativa era diversificada e destinada a apoiar as aprendizagens, havendo momentos de auto e heteroavaliação. Como é óbvio, estas condições só puderam ser criadas porque a planificação, a organização e as práticas de ensino estiveram estreitamente articuladas, ou mesmo integradas, com a avaliação e com as aprendizagens. Efetivamente, tal como tem vindo a ser sublinhado por vários autores (e.g. BLACK; WILIAM, 1998; GARDNER, 2006; BRYAN; CLEGG, 2006; FALCHICOV, 2005), não faz qualquer sentido considerar os processos de ensino, de avaliação e de aprendizagem como se constituíssem entes de mundos diferentes e, por isso, encontrar novas e inovadoras formas de avaliar os alunos implicará sempre transformações profundas nas formas de organizar e desenvolver o ensino e vice-versa.

Na referida síntese de literatura, Fernandes e Fialho (2012) produziram um conjunto de conclusões de que se destacam as que se apresentam e discutem em seguida.

\section{Tarefas de avaliação utilizadas}

Em cada uma das investigações analisadas (e.g. BLOXHAM; WEST, 2004; CARLESS, 2002; GIBELS et al., 2008; KLENOWSKI et al., 2006; MILLER, 2009) utilizaram-se preferencialmente duas ou mais tarefas de avaliação, tais como testes, apresentações orais, trabalhos escritos de diferentes naturezas (e.g. relatórios, composições, reflexões, comentários), posters e portefólios. A realização das tarefas era em geral indissociável de processos de interação entre alunos e entre estes e o docente, de reflexões críticas partilhadas, de distribuição de feedback, da utilização de tutorias e de dinâmicas de ensino e de aprendizagem diversificadas.

\section{Participação dos alunos}

De acordo com a literatura revista (e.g. BALLANTYNE et al., 2002; DANCER; KAMVOUNIAS, 2005; JOHNSTON; MILES, 2004; NICOL, 2009; POON et al., 2009), os alunos participaram nos processos de avaliação de forma mais ou menos sistemática e de acordo com as seguintes dinâmicas: a) Peque- 
nos grupos de trabalho em que se procuravam desenvolver formas de trabalho colaborativo, processos de comunicação e feedback entre pares, de análise conjunta de tarefas e de planeamento e gestão do tempo; b) Envolvimento dos alunos, sobretudo ao nível do grande grupo, na discussão e definição de critérios de avaliação das tarefas que lhes eram propostas, tendo em vista que os alunos poderiam compreender melhor o que lhes era pedido, incentivando-os a serem mais críticos e autónomos no desenvolvimento das suas aprendizagens; e c) Participação dos alunos em processos de auto e heteroavaliação tendo em vista, entre outros objetivos, o desenvolvimento das suas competências metacognitivas e de regulação e de autorregulação das suas aprendizagens.

\section{Natureza e frequência do feedback}

De modo geral o feedback era preferencialmente distribuído pelos professores, verbalmente ou por escrito, sendo de referência criterial e com uma diversidade de propósitos, tais como informar, corrigir, motivar, orientar, regular e mesmo classificar o desempenho dos alunos. (e.g. CARLESS, 2002; MACMILLAN; MCLEAN, 2005; TROTTER, 2006). A sua frequência estava associada à natureza das tarefas que os alunos tinham que resolver e, por isso, os portefólios, a resolução de problemas complexos e o desenvolvimento de projetos exigiam normalmente feedback mais frequente do que a elaboração de uma composição. Os alunos também eram envolvidos na distribuição de feedback, apoiados em listas de verificação, tabelas e outros instrumentos, que incidia sobre os produtos realizados pelos colegas ou sobre a sua participação e atitudes no desenvolvimento do trabalho de grupo. (e.g. ORSMOND et al., 2002; WALKER; WARHURST, 2000; WANOUS et al., 2009).

\section{Natureza e utilizações da avaliação}

Na maioria dos estudos analisados a avaliação era de referência criterial e tinha como principais propósitos contribuir para que os alunos regulassem e autorregulassem as suas aprendizagens. A ideia mais preponderante na literatura revista era a de que a avaliação do dia a dia, integrada e/ou articulada com o ensino e com as aprendizagens deveria estar a serviço dos alunos, ajudando-os 
a aprender e a compreender melhor e a orientar o seu trabalho. Ou seja, a avaliação era em geral formativa por natureza e estava associada igualmente aos processos de auto e heteroavaliação que, como já se referiu, contribuíam para que os alunos desenvolvessem hábitos de reflexão crítica acerca do seu trabalho. (e.g. ANDRADE; DU, 2007; DANCER; KAMVOUNIAS, 2005; KLENOWSKI et al., 2006; MOK et al., 2006; POON et al., 2009). Importa referir que as tarefas que eram utilizadas com fins sumativos no final dos períodos letivos (e.g. ensaios, projetos, exames) tinham normalmente uma maior ponderação para efeitos de classificação do que as tarefas com os mesmos fins mas que eram utilizadas ao longo do referido período. (e.g. COOK, 2001; GALE et al., 2002; NICOL, 2009; TARAS, 2002). Em suma e de modo geral, as avaliações tinham as seguintes utilizações principais: a) orientar o trabalho dos alunos, apoiando o desenvolvimento das suas aprendizagens; b) melhorar as suas competências metacognitivas; e c) certificar os seus conhecimentos e competências.

\section{Inovação e práticas de avaliação}

A grande maioria dos participantes nas investigações analisadas considerou que as mudanças introduzidas nas práticas de avaliação influenciaram positivamente quer os processos de ensino quer as aprendizagens dos alunos. As tutorias foram bastante destacadas porque contribuíram para o desenvolvimento de processos complexos de pensamento e para que os alunos compreendessem bem, através do feedback que lhes era distribuído sistematicamente, o que, e como, tinham que aprender. (e.g. ANDRADE; DU, 2007; ALBERTINO; DE SOUSA, 2004; CARLESS, 2002; KLENOWSKI et al., 2006; MACMILLAN; MCLEAN, 2005). A clarificação dos critérios de avaliação revelou-se igualmente associada à melhoria das aprendizagens dos alunos que aprenderam a utilizá-los quer na distribuição de feedback pelos seus colegas quer ainda nos processos de auto e heteroavaliação, que os ajudaram a centrarem-se no que tinham que aprender e a melhorar a sua motivação e as suas capacidades metacognitivas, de análise e de autorregulação. (e.g. JOHNSTON; MILES, 2004; KLENOWSKI et al., 2006; MOK et al., 2006; ORSMOND et al., 2002; PRICE; O'DONOVAN, 2006). A avaliação por pares foi igualmente considerada uma boa estratégia para apoiar as aprendizagens e para avaliar a participação individual dos alunos nos trabalhos que tinham que fazer em pequenos grupos. (e.g. BALLANTYNE et al., 2002; BERG et al., 2006; BLOXHAM; WEST, 2004; JOHNSTON; MILES, 2004). 


\section{Nota final}

O que se pode afirmar nesta altura é que temos hoje uma base empírica suficientemente sólida para afirmar que os alunos do ensino superior podem aprender mais e melhor, com mais profundidade e compreensão, se as práticas de avaliação e de ensino forem modificadas no sentido que tem sido ilustrado pela literatura. Na verdade, os resultados das pesquisas que se analisaram foram geralmente muito positivos e encorajadores, sobretudo porque mostraram que a participação ativa dos alunos nos processos de avaliação e de aprendizagem conduz invariavelmente ao desenvolvimento das capacidades mais complexas de pensamento e a aprendizagens mais significativas. As práticas sistemáticas de auto e de heteroavaliação revelaram-se fundamentais porque permitiram que, em cada momento, os alunos compreendessem em que situação se encontravam e o que, e como, tinham que aprender.

\section{Problema e questões da investigação}

O problema desta pesquisa decorreu da constatação, amplamente identificada e reconhecida na literatura, de que o trabalho empírico realizado nas salas de aula do ensino superior é fundamental para que se conheçam e compreendam mais profundamente as práticas docentes. Só desta forma se pode encontrar uma racionalidade que contribua para teorizar e melhorar as práticas. Como já se viu anteriormente, os resultados da síntese de literatura recentemente realizada por Fernandes e Fialho (2012) e de outras investigações (e.g. BRYAN; CLEGG, 2006; BOUD, 2000; DANCER; KAMVOUNIAS, 2005; FALCHIKOV, 2005) mostraram que é possível melhorar as práticas de avaliação e de ensino no contexto do ensino superior e, assim, melhorar substancialmente o que, e como, os alunos aprendem. A participação ativa dos alunos nos processos de avaliação e aprendizagem, as práticas de auto e heteroavaliação e a qualidade das interações que se estabelecem nas salas de aula, são algumas das condições necessárias para melhorar a qualidade das aprendizagens no ensino superior.

Nessas condições, esta investigação que, como se referiu inicialmente, se circunscreveu apenas ao contexto de duas unidades curriculares (disciplinas) de duas licenciaturas da área das Artes e Humanidades, foi desenvolvida tendo em conta as seguintes questões orientadoras: 
a. Como estava organizado e estruturado o ensino e que dinâmicas de sala de aula se puderam identificar?

b. Qual a natureza das tarefas de ensino e avaliação mais utilizadas e qual o papel que alunos e professores desempenharam na sua resolução?

c. Em que medida foi utilizado feedback? Qual era a sua natureza e com que frequência era distribuído pelos alunos?

d. De que formas é que professores e alunos utilizavam a avaliação e quais eram os seus propósitos mais relevantes?

\section{Método}

Tal como foi referido na Introdução, a pesquisa que aqui se relata foi exclusivamente baseada nas entrevistas a professores e a alunos e nas observações das aulas de duas unidades curriculares - Desenho e História da Arte - do domínio das Artes e Humanidades numa das sete universidades participantes no projeto. Tratou-se de uma pesquisa de natureza eminentemente qualitativa que ocorreu na já mencionada Fase Intensiva da pesquisa mais abrangente. Ou seja, nesta fase, procedeu-se a uma imersão nas salas de aula e a uma interação com os participantes tendo em vista procurar compreender os significados por estes atribuídos aos fenómenos pedagógicos em que estavam envolvidos e de que eram os principais protagonistas. Desta forma, pretendeu-se descrever, analisar e interpretar todas as ações, pensamentos e artefatos que pudessem contribuir para conhecer e compreender práticas de ensino e de avaliação que ocorreram nas aulas observadas.

\section{Matriz de investigação}

Tendo em conta a complexidade dos elementos envolvidos, elaborou-se uma Matriz da Investigação em que o Ensino, a Avaliação e a Aprendizagem eram os objetos fundamentais. Para cada um destes objetos foi considerada uma diversidade de dimensões. Assim, para o Ensino foram tidas em conta dimensões tais como: Planificação e Organização do Ensino, Tarefas e Natureza das Tarefas, Dinâmicas de Sala de Aula e a Natureza, Frequência e Distribuição de Feedback. No que se refere à Avaliação incluíram-se dimensões tais como: 
Tarefas de Avaliação Mais Utilizadas, Funções da Avaliação, Integração ou Articulação dos Processos de Ensino, Aprendizagem e Avaliação e Recurso a Estratégias de Auto e Heteroavaliação. No Quadro 2 apresenta-se a versão da matriz que foi utilizada para os objetos Ensino e Avaliação. Deve notar-se que esta organização é algo artificial e, por isso, há dimensões que podem ser consideradas em mais do que um objeto. Ou seja, na prática, facilmente se constata que o ensino, a aprendizagem e a avaliação são processos naturalmente agregados e nem sempre é possível separar claramente o que são ações de um ou outro processo.

QUADRO 2 - MATRIZ UTILIZADA NA PESQUISA DE PRÁTICAS DE ENSINO E AVALIAÇÃO

\begin{tabular}{|c|c|}
\hline Objetos & Dimensões \\
\hline \multirow{10}{*}{ Ensino } & Planificação e Organização do Ensino \\
\hline & Recursos e Materiais Utilizados \\
\hline & Tarefas e Natureza das Tarefas \\
\hline & Gestão do Tempo e Estruturação da Aula \\
\hline & Dinâmicas de Sala de Aula \\
\hline & Papel dos Professores e Alunos \\
\hline & Natureza, Frequência e Distribuição de Feedback \\
\hline & Perceções dos Professores \\
\hline & Perceções dos Alunos \\
\hline & Ambiente de Sala de Aula \\
\hline \multirow{10}{*}{ Avaliação } & Tarefas de Avaliação Mais Utilizadas \\
\hline & Funções da Avaliação \\
\hline & Natureza da Avaliação \\
\hline & Utilidade da Avaliação \\
\hline & Articulação Entre os Processos de Ensino/Avaliação/Aprendizagem \\
\hline & Natureza, Frequência e Distribuição de Feedback \\
\hline & Papel dos Professores e Alunos \\
\hline & Recurso a Estratégias de Auto e Heteroavaliação \\
\hline & Perceções dos Professores \\
\hline & Perceções dos Alunos \\
\hline
\end{tabular}

FONTE: O autor (2015).

A Matriz da Investigação revelou-se fundamental para focar a pesquisa, para apoiar os pesquisadores a estabelecerem e a compreenderem relações entre todos os seus elementos e para produzir os guiões de observação e de entrevistas semiestruturadas que foram utilizadas na recolha dos dados. 


\section{Recolha, integração e transformação dos dados}

Participaram na investigação os dois docentes responsáveis por cada uma das referidas unidades curriculares e os seus alunos. Todos integraram a pesquisa voluntariamente, disponibilizando-se para receberem os investigadores nas suas aulas e para serem entrevistados. As observações decorreram ao longo de cerca de 20 horas em cada uma das aulas, ambas de natureza teórico-prática. As entrevistas aos professores e aos alunos decorreram no final do semestre, tendo cada uma tido a duração de cerca de uma hora. Os alunos foram entrevistados em dois focus groups, um com cinco alunos de uma sala e outro com quatro alunos da outra sala.

Em todas as aulas observadas os pesquisadores permaneceram sentados no fundo das salas, tomando notas e agindo sempre como observadores não participantes. Quer as observações quer as entrevistas a alunos e professores foram apoiadas em guiões semiestruturados que foram construídos com base na Matriz da Investigação através de um processo de interação, discussão e partilha que envolveu algumas dezenas de intervenientes.

Após o processo de recolha dos dados foram produzidos os seguintes seis documentos (três por cada professor participante): a) Duas narrativas correspondentes a cerca de 20 horas de observações em cada aula; b) Duas narrativas correspondentes às entrevistas realizadas aos dois grupos de alunos; e c) Duas narrativas correspondentes às entrevistas realizadas a cada um dos dois professores. Este material, depois de analisado e interpretado tendo em conta a matriz de investigação e os guiões acima referidos, deu origem a duas narrativas, uma para cada um dos professores (Para efeitos do trabalho aqui apresentado utilizaram-se sobretudo estas narrativas produzidas para cada um dos docentes participantes na pesquisa.). Finalmente, a partir destas, obteve-se uma única Narrativa Integrada Global que resultou da organização e integração da informação considerada mais relevante e que foi, sobretudo, utilizada para efeitos da pesquisa mais global a que se fez referência na Introdução. A Figura 1 ilustra de forma esquemática este procedimento.

Interessa igualmente fazer referência aos procedimentos que foram utilizados para transformar os dados referentes às observações e às entrevistas aos professores e aos alunos e que permitiram produzir as respetivas narrativas. Para o efeito, foram tidas em conta, por um lado, as dimensões constantes na Matriz da Investigação e nos guiões de entrevista e de observação e, por outro lado, cada uma das fontes de recolha de dados referentes a cada professor (observações e entrevistas a professores e alunos). Desta forma, para cada 
FIGURA 1 - VISÃO ESQUEMÁTICA DO PROCESSO DE TRANSFORMAÇÃO DE DADOS RELATIVO A CADA UM DOS DOIS PROFESSORES

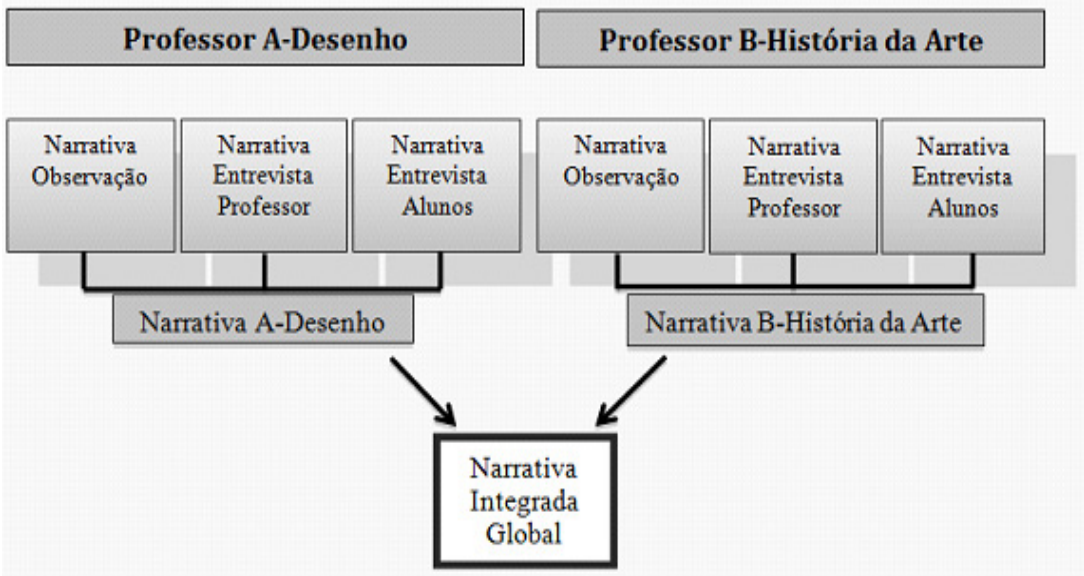

FONTE: O autor (2015).

dimensão considerada (e.g. Tarefas e Natureza das Tarefas, Dinâmicas de Sala de Aula, Natureza, Frequência e Distribuição do Feedback), procedeu-se a uma análise horizontal ao longo das fontes de recolha de dados mencionadas. Este procedimento permitiu obter, para cada dimensão, uma Síntese Horizontal que resultou da integração da informação proveniente de cada uma das fontes de recolha de informação. Além disso, realizou-se uma análise vertical dos dados provenientes de cada uma das fontes de recolha de informação ao longo de todas as dimensões consideradas, obtendo-se assim três Sínteses Verticais para cada professor. Em suma, foram elaboradas sínteses para cada dimensão (horizontais) e sínteses para cada fonte de recolha de informação (verticais). Foi a partir das Sinteses Verticais que se elaboraram as narrativas que já se referiram acima. As Sínteses Horizontais contribuíram para a elaboração da Síntese Global. A Figura 2 permite visualizar o processo de transformação dos dados.

Os dados foram agregados e transformados tendo em conta o trabalho e as recomendações de Erickson (1986), Merriam (1988) e Wolcott (1994). 
FIGURA 2 - EXEMPLO DO PROCESSO UTILIZADO NA TRANSFORMAÇÃO DOS DADOS CONSIDERANDO TRÊS DIMENSÕES E CADA UM DOS PROCESSOS DE RECOLHA DE INFORMAÇÃO REFERENTE ÀS PRÁTICAS DE CADA PROFESSOR

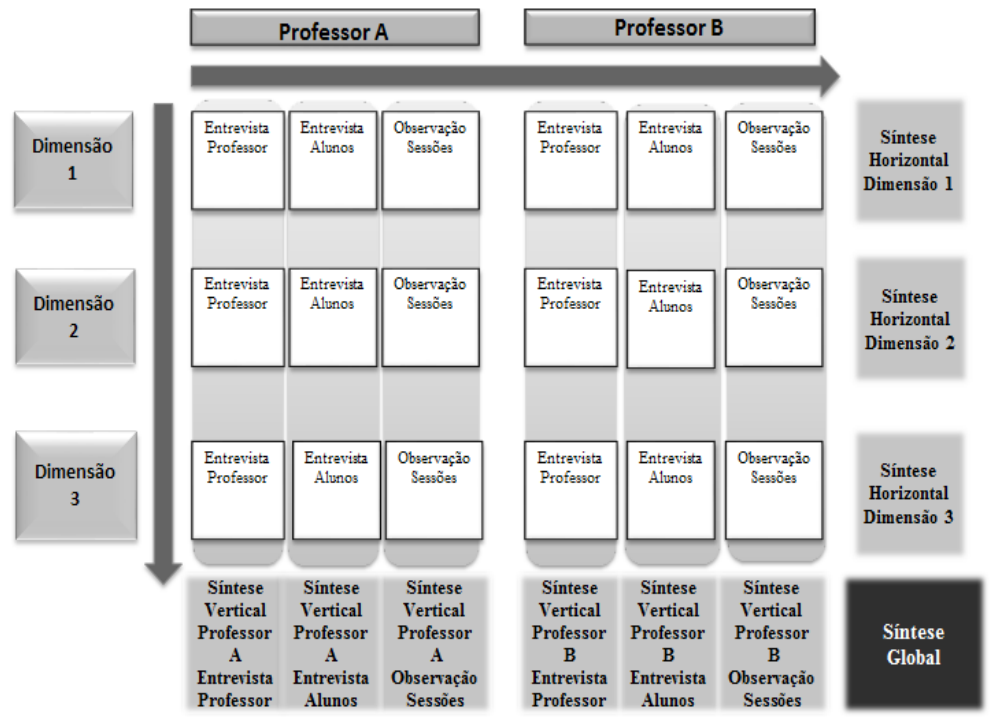

FONTE: O autor (2015).

\section{Apresentação e discussão dos principais resultados}

Ensino e dinâmicas de sala de aula

Cada um dos dois professores participantes manteve uma estrutura de aula consistente, bem definida e com encadeamento lógico, sugerindo que todas as aulas eram objeto de uma planificação e preparação cuidadas. No entanto, a estrutura e as dinâmicas existentes nas duas salas de aula, assim como a gestão do tempo, foram significativamente diferentes.

O docente de Desenho, em geral, estruturava as suas duas aulas semanais de três horas cada uma em seis momentos distintos mas relacionados: a) síntese da aula anterior; b) breve introdução teórica para fundamentar as técnicas e abordagens a privilegiar; c) trabalho individual e autónomo dos alunos assistido pelo docente; d) balanço do trabalho desenvolvido após o decurso de metade 
da aula; e) trabalho individual e autónomo dos alunos assistido pelo docente; e f) balanço final do trabalho desenvolvido. Esta estrutura, por natureza, gerou diferentes dinâmicas de trabalho e de participação dos alunos nas atividades da aula. Na verdade, ainda que a maior parte do tempo de aula fosse passada com os alunos a desenhar individualmente, havia momentos para interação entre o professor e cada um dos seus alunos e momentos em que estes tinham a possibilidade de apreciar e refletir acerca do trabalho desenvolvido por si e pelos seus colegas. Os alunos pareciam apreciar as dinâmicas postas em prática, assim como os momentos de reflexão e de interação com o professor.

Por seu lado, o docente de História da Arte utilizou uma estrutura para as suas duas aulas semanais, de duas horas cada uma, que se traduzia em dois momentos distintos: a) um primeiro momento, geralmente breve, em que o docente fazia uma síntese dos assuntos mais relevantes da aula anterior; e b) um segundo momento, que ocupava a maior parte do tempo de aula, que o docente utilizava quase integralmente para expor os assuntos previstos no programa da unidade curricular. Desta forma, pode dizer-se que, no essencial, a única dinâmica existente nestas aulas consistiu na exposição das matérias por parte do docente enquanto os alunos tomavam notas do que iam ouvindo. Durante o período de 20 horas de observação, não houve praticamente qualquer tipo de interação entre os alunos e entre estes e o professor. Na verdade, o docente, um excelente comunicador, não utilizou quaisquer estratégias que suscitassem a participação dos alunos em qualquer discussão. A este propósito referiu, por um lado, que os alunos eram "pouco participativos" e, por outro, que a participação dos alunos nas aulas iria dificultar a oportunidade para ouvirem o que o docente "tinha para lhes ensinar". Assim, as aulas assemelhavam-se a palestras eloquentes, em que o docente produzia um discurso bem articulado e se sentia claramente à vontade, sempre apoiado em conjuntos de transparências que reproduziam as obras de arte que tinham que ser estudadas. Os alunos entrevistados não se mostraram particularmente satisfeitos com esta abordagem de ensino, chegando a considerar que não aprendiam nas aulas aquilo que esperavam, mas também não revelaram possuir um pensamento elaborado acerca de possíveis alternativas.

\section{Tarefas de ensino e avaliação e papel dos alunos e dos professores}

Também no que se refere às tarefas utilizadas e ao papel desempenhado pelos docentes e alunos verificou-se uma significativa diferença nas abordagens utilizadas pelos dois docentes que, aliás, se revelou consistente com a natureza do ensino que cada um desenvolveu.

Nas aulas de Desenho as tarefas eram diversificadas e iam sendo sugeridas pelo professor de aula para aula, a partir de um conjunto invariável de objetos que 
se encontrava no meio da sala. No essencial consistiam na realização de desenhos a partir da observação, permitindo que os alunos fossem aprendendo diferentes abordagens e técnicas e, em rigor, cumpriam funções de aprendizagem, ensino e avaliação. Na opinião dos alunos, permitiam uma "boa relação entre a teoria e a prática". Todas as tarefas estavam orientadas para que os alunos desenvolvessem técnicas de desenho e lidassem com aspetos tais como as formas, as sombras e as cores. As dinâmicas da sua utilização facilitavam a definição dos papéis que os alunos e o docente desempenhavam no desenvolvimento e na articulação daqueles três processos. Ao manter um sistema consistente e sistemático de distribuição de feedback por cada um dos seus alunos, o docente conseguia que as tarefas pudessem ser utilizadas como meio privilegiado de aprendizagem. Dito de outra forma, a avaliação de natureza formativa sobre o trabalho desenvolvido com as tarefas foi efetivamente utilizada para ajudar os alunos a aprender. Deste modo, os alunos puderam assumir um papel ativo e bastante autónomo na construção das suas aprendizagens, valorizando as intervenções do professor que agia como um distribuidor de feedback de qualidade, proporcionando momentos de reflexão, de sistematização e de síntese acerca do que era necessário aprender e saber fazer. Nestas condições, os alunos tinham necessariamente que trabalhar sobre as tarefas para poderem aprender e para progredirem academicamente. Além disso, o professor pedia que os alunos fizessem trabalhos fora do tempo das aulas, tarefas que estes valorizavam porque, nas suas palavras, permitiam-lhes aprender e compreender de forma mais autónoma e ganhar perspetivas sobre outros modos de aprender. Estes trabalhos eram objeto de análise e avaliação por parte do professor. Igualmente valorizado pelos alunos foi o facto de o docente partilhar com eles uma diversidade de livros e utilizar uma variedade de imagens que, na sua opinião, eram importantes contributos para aprender e para se sentirem mais motivados. De fato, o docente manifestou claramente a preocupação de projetar imagens, que organizava no seu $i \mathrm{Pad}$, fazendo questão que elas fossem analisadas por todos os alunos.

Em síntese, o docente de Desenho desenvolvia o currículo articulando e integrando a avaliação, o ensino e as aprendizagens. A avaliação do dia a dia, designada como Avaliação Continuada, estava intrinsecamente associada às tarefas a desenvolver pelos alunos e servia essencialmente para os ajudar a aprender. Era a modalidade de avaliação claramente predominante. A chamada Avaliação Periódica consistia na realização de pontos de situação, de balanços, em que o docente avaliava os trabalhos de cada um dos alunos, proporcionando momentos de reflexão e análise que podiam ocorrer individual ou coletivamente. Estes balanços ou pontos de situação, designados como Avaliações Intermédias, ocorreram sensivelmente a meio e no final do semestre. Finalmente, a Avaliação Final era apenas realizada por alunos que estivessem com dificuldades ou 
por alunos muito bons ou excecionais. Nestes casos, a avaliação era realizada por um júri de docentes da unidade curricular que analisavam e discutiam com os alunos os trabalhos realizados. É interessante referir que, na entrevista, os alunos só identificaram a avaliação que ocorria com o desenvolvimento das tarefas (avaliação continuada) quando instados a pronunciarem-se sobre ela. Numa primeira abordagem a avaliação era apenas identificada com as avaliações intermédias e finais e não como um processo para apoiar o desenvolvimento das tarefas articulado com o ensino e as aprendizagens.

Nas aulas de História da Arte a abordagem utilizada pelo docente, essencialmente baseada na exposição das matérias que os alunos tinham que aprender, não previa quaisquer tarefas para serem trabalhadas pelos alunos no contexto da sala de aula. Assim, nas aulas, as oportunidades para aprender decorriam do discurso do professor, sempre muito associado às transparências que ia projetando através da aplicação PowerPoint. Na verdade, os alunos limitavam-se a tomar notas não tendo, na grande maioria das aulas, qualquer participação digna de registo. $\mathrm{O}$ docente admitiu que teria dificuldade em gerir o ensino baseado em tarefas porque, sendo especialista na matéria, não via como é que os alunos poderiam aprender dessa forma sem que ele lhes transmitisse os conhecimentos a adquirir. Além disso, na sua opinião, a utilização de tarefas para serem desenvolvidas pelos alunos estava inviabilizada pela falta de tempo decorrente da redução do tempo letivo motivada pela aplicação do processo de Bolonha.

Os alunos pareceram sempre bastante tranquilos, em silêncio, abstendo-se de qualquer tipo de participação. Mesmo a comunicação não verbal pareceu ausente na maioria das aulas observadas pois, por um lado, o professor desenvolvia o seu discurso percorrendo os corredores entre as carteiras sem chegar a estabelecer esse tipo de comunicação e, por outro lado, os alunos tinham os olhos fixados nas folhas onde escreviam as suas notas. Além do mais, a sala estava sempre bastante escurecida porque se os estores não estivessem praticamente fechados a luz, que à hora da aula era bastante intensa, impedia uma boa visualização das transparências. Dir-se-ia que, ao longo das 20 horas de observações, alunos e professor interagiram verbalmente cerca de 4 a 5 minutos no máximo. Nestas condições, não houve quaisquer dinâmicas de aprendizagem visíveis que implicassem a participação e o envolvimento ativo dos alunos. No entanto, dadas as características evidenciadas pelo professor (e.g. discurso claro, consistente, coerente e cativante, entusiasmo, domínio dos assuntos) e as suas referências a livros para consultar e a obras de arte que poderiam ser observadas e analisadas, é provável que os alunos, ou uma parte deles, se sentissem motivados para aprender para além das aulas.

Os alunos entrevistados limitaram-se a referir que tinham que estudar bastante e efetuar pesquisas que lhes permitissem ter acesso à informação de 
que necessitavam para desenvolver as tarefas de avaliação que constavam no programa: a) uma ficha que o professor utilizava com propósitos diagnósticos; b) um trabalho final, com cerca de 30/40 páginas, subordinado a um determinado tema; e c) um teste. Relativamente a qualquer destas tarefas, os alunos pareceram confusos quanto aos critérios de avaliação utilizados e quanto à ponderação de cada uma para efeitos da classificação final. Quer o trabalho final quer o teste eram exclusivamente utilizados para classificar os alunos e, por isso, pode dizer-se que a avaliação nas aulas de História da Arte era de natureza sumativa. $\mathrm{Na}$ verdade, a avaliação não estava articulada com os processos de ensino e de aprendizagem, constituindo um processo à parte destinado a recolher informação para a classificação. Na entrevista, no entanto, o docente referiu que se disponibilizava sempre junto dos alunos para acompanhar o desenvolvimento do seu trabalho final podendo assim ir proporcionando feedback. Mas os alunos não solicitavam esse tipo de acompanhamento porque, provavelmente, iniciavam a realização do trabalho após o final do semestre letivo. Assim, as tarefas de avaliação eram integralmente realizadas pelos alunos com pouca ou nenhuma interação com o professor e/ou com os colegas sendo, por isso mesmo, orientadas exclusivamente para que se formulasse um juízo final acerca do que os alunos sabiam e eram capazes de fazer.

Apesar de não manifestarem abertamente as suas opiniões e perceções acerca das tarefas de ensino e de avaliação e dos papéis desempenhados pelo docente e por si próprios, os alunos sempre foram dizendo que a "forma como as coisas decorriam" não lhes parecia a "mais eficaz". Sobretudo porque não havia participação em qualquer discussão e porque o docente se concentrou num número limitado de temas, deixando outros que lhes pareciam importantes por abordar. Além disso, referiram que a dinâmica e as estratégias de ensino e avaliação utilizadas não "resultaram muito bem porque se tirava muito pouco das aulas". Na opinião dos alunos as aulas eram muito repetitivas, acabando por não ter oportunidade de aprender outras coisas igualmente importantes que não teriam sido dadas. No entanto, reconheceram que, "com o processo de Bolonha", havia cada vez menos tempo para dar tudo o que seria supostamente aconselhável.

\section{Natureza, utilização e distribuição do feedback}

Os dados obtidos através das observações e das entrevistas aos alunos e ao docente de Desenho permitiram identificar três aspetos fundamentais relativamente ao feedback que foi distribuído ao longo de cada uma das aulas. Em primeiro lugar, o feedback fazia parte integrante dos processos de ensino, avaliação e aprendizagem, ocorrendo frequentemente em todas as aulas quando 
se considerava necessário e/ou oportuno. Em segundo lugar, o feedback era essencialmente individual, distribuído verbalmente a cada um dos alunos ao longo das aulas. Porém, o número elevado de alunos na turma, cerca de 50, nem sempre permitia que, numa só aula, o docente pudesse distribuir feedback a todos os alunos. Em terceiro lugar, ficou muito claro que ofeedback tinha um propósito eminentemente orientador e regulador das atividades a desenvolver pelos alunos, ajudando-os a reorientar e a melhorar o seu trabalho, corrigindo erros e articulando perspetivas teóricas com a realização concreta dos trabalhos práticos. Por isso se pode afirmar que a avaliação de natureza formativa foi predominante em todas e em cada uma das aulas de Desenho.

De acordo com os alunos e com o que foi possível observar, o feedback foi utilizado para orientar e/ou reorientar os seus percursos tendo em conta as tarefas que tinham que desenvolver. Talvez por isso mesmo o docente tivesse referido que ofeedback ocupava um lugar de destaque nas funções de ensino que tinha que desempenhar. Por seu lado, os alunos reconheceram que era através da utilização que davam ao feedback que melhoravam o seu trabalho e aprendiam o que eram supostos aprender. Nomeadamente através da análise de imagens e ilustrações e das reflexões que eram feitas nas aulas e fora delas.

No âmbito da unidade curricular de História da Arte a natureza do ensino, a estruturação das aulas, as dinâmicas de participação e o papel destinado ao docente e aos alunos não eram propriamente favoráveis à existência de feedback que, por exemplo, ajudasse os alunos a orientar e a reorientar o seu trabalho académico. $\mathrm{O}$ docente tinha a este propósito uma posição bastante clara: na sequência do processo de Bolonha e por força da redução dos tempos letivos, não havia tempo para que os alunos trabalhassem, individualmente ou em grupo, sobre determinadas tarefas, nem havia tempo para que procedessem a apresentações de textos ou de obras de arte. Consequentemente, o feedback seria distribuído no decorrer do acompanhamento do trabalho final e sob a forma da atribuição da classificação final. No entanto, como já acima se referiu, os alunos não procuravam o apoio do professor para elaborarem aquele trabalho $\mathrm{e}$, por isso, o feedback não fez parte dos processos de ensino, aprendizagem e avaliação, limitando-se a uma classificação no final do semestre.

De acordo com os dados apurados nesta pesquisa os alunos não receberam qualquer tipo de feedback ao longo do semestre letivo relativamente às tarefas de avaliação que desenvolveram e que estavam previstas no programa. Ou seja, os alunos só puderam ter uma ideia acerca do seu desempenho nas referidas tarefas quando tomaram conhecimento da sua classificação final na unidade curricular. Mas também reconheceram que não procuraram o docente para obter qualquer feedback relativamente ao desenvolvimento do trabalho final, tarefa privilegiada para que esse processo pudesse ocorrer de forma individualizada. 
Por seu lado, o docente também não desenvolveu ações concretas para que pudesse ser de outro modo. Manifestou a sua disponibilidade mas, na ausência de alunos, parece não ter tomado quaisquer decisões que alterassem a situação.

\section{Propósitos e utilizações da avaliação}

De acordo com os dados recolhidos no âmbito das aulas de Desenho foram identificadas as seguintes utilizações principais da avaliação: a) melhorar e/ou regular o ensino e as aprendizagens; b) identificar os alunos que precisavam de maior acompanhamento por parte do docente; e c) classificar e diferenciar os alunos tendo em conta o seu esforço, o seu trabalho, as suas capacidades e os seus resultados. Verificou-se assim que, tal como já se referiu anteriormente, a avaliação foi utilizada com propósitos formativos e sumativos e, consequentemente, para apoiar e certificar, classificando, as aprendizagens dos alunos. Foi interessante verificar que os alunos referiram que a avaliação tinha sido importante para os ajudar a situar relativamente ao ponto em que se encontravam em relação aos objetivos que tinham que alcançar e àquilo que tinha sido alcançado pelos seus colegas. Assim, os alunos identificaram quer a referência criterial quer a referência normativa da avaliação. Por outro lado, os alunos também afirmaram que a avaliação lhes permitiu clarificar o que era necessário aprender, ajudando-os a definir as suas estratégias de estudo e, em geral, os seus comportamentos como estudantes. Por seu lado, o docente de Desenho, para além de se ter referido aos propósitos formativos da avaliação, mencionando a sua utilização reguladora e autorreguladora, sublinhou os seus propósitos sumativos e utilizações, tais como fazer pontos de situação, diferenciar os alunos, premiar o mérito, reconhecer o esforço e "penalizar os que trabalham menos". Não deixa de ser interessante a referência a esta última utilização por parte de um docente que, na prática, privilegiava claramente as funções e as utilizações formativas da avaliação.

Por fim, é importante sublinhar que a predominância da avaliação formativa e de dinâmicas de ensino que implicavam a participação ativa dos alunos criou condições para que os processos de auto e heteroavaliação fizessem parte das rotinas pedagógicas instaladas nas aulas de Desenho. Consequentemente, os alunos tinham oportunidades regulares para refletirem acerca dos seus progressos e dificuldades e acerca dos trabalhos dos seus colegas. Estes processos foram reconhecidos pelos estudantes como relevantes para o desenvolvimento das suas aprendizagens e das suas competências para analisar, sintetizar e avaliar.

No âmbito da unidade curricular de História da Arte os dados recolhidos mostraram que a principal, talvez a única, utilização que foi dada à avaliação foi a de classificar e certificar as aprendizagens supostamente desenvolvidas 
pelos alunos. Apesar de o docente referir que dava uma utilização diagnóstica à primeira tarefa de avaliação solicitada aos alunos (um trabalho escrito individual centrado na crítica a um texto), os dados obtidos não sugerem essa utilização. Além disso, o docente fez referência a utilizações tais como "detetar dificuldades", "aferir conhecimentos" e "adaptar o ensino à turma que leciona" que, de igual modo, não foram perceptíveis através dos dados recolhidos nesta pesquisa. Os alunos revelaram-se bastante críticos em relação aos hipotéticos propósitos e utilizações da avaliação, sobretudo porque não os conseguiram compreender nem sentir, na prática, os seus efeitos. Curiosamente, centraram as suas preocupações nas classificações que, na sua opinião, não refletiam as diferenças existentes na turma. Talvez por isso, chegaram a referir que a avaliação também não era utilizada para os classificar. Para além disso, os alunos não conseguiram vislumbrar que a avaliação pudesse ser um processo que os orientasse e ajudasse a aprender porque desconheciam "as regras" (e.g. critérios de avaliação, processos de classificação utilizados, ponderação das diferentes tarefas para efeitos de classificação).

Em suma, a análise global dos dados mostrou que nem os alunos nem o docente de História de Arte Moderna utilizaram a avaliação para apoiar e/ou melhorar o ensino e as aprendizagens. Na verdade, pode dizer-se que o processo de avaliação pouco ou nada teve a ver com a organização do ensino e o desenvolvimento das aprendizagens. Ainda que os alunos não compreendessem a sua utilização na atribuição de classificações, parece ter sido esta a sua utilização mais evidente. Tratou-se, por isso, de uma avaliação que se pode considerar pobre e desligada de outros processos pedagógicos tão cruciais como o ensino e a aprendizagem.

\section{Conclusões e reflexões}

O principal propósito desta pesquisa era o de compreender práticas de ensino e de avaliação de docentes do ensino superior a partir de narrativas construídas com base na observação de um significativo número de aulas (40 horas no total) e em entrevistas realizadas junto a dois grupos de alunos e a cada um dos docentes participantes. Mais do que comparar as práticas dos dois docentes, ainda que tal possa ser praticamente impossível de evitar, importa compreendê-las através dos modos como se pode estruturar e organizar o ensino, das tarefas selecionadas e dos papéis que docentes e alunos assumem no 
processo da sua resolução, da natureza do feedback utilizado e dos propósitos e utilizações da avaliação.

De acordo com o esquema conceitual de Escudero (2012), apresentado e discutido anteriormente, esta pesquisa realizou-se ao nível individual (micro) no contexto da sala de aula sendo a unidade de análise as práticas dos docentes participantes. As observações das aulas e as conversas formais e informais com os docentes não permitiram, no entanto, identificar inequivocamente qualquer um deles com uma das dimensões previstas por Escudero (técnica, reflexiva, crítica). O que se pode afirmar nesta altura é que ambos agiam deliberadamente, mas sem uma base conceitual pedagógica consciente. Isto é, as suas práticas pareceram estar muito mais associadas às suas intuições, às suas conceções e a formas de raciocínio que, do seu ponto de vista, lhes permitiam resolver os problemas que tinham que ir resolvendo e não pareceram ser facilmente encaixáveis numa daquelas três dimensões. Poderá eventualmente dizer-se que se identificaram traços "técnicos" e "reflexivos" em ambos os docentes, ainda que as suas abordagens ao ensino tivessem sido marcadamente distintas. Estas e outras questões, que não caberá analisar neste contexto, merecem ser aprofundadas e discutidas pois enquadramentos como o que nos propõe aquele pesquisador podem ser bastante úteis no estudo da docência universitária.

Esta pesquisa veio confirmar que as salas de aula são espaços que podem ser decisivos na introdução de novas e inovadoras formas de organizar e estruturar o ensino e a avaliação de forma a que os alunos possam aprender mais e, sobretudo melhor, com compreensão e profundidade. Os docentes, ainda que em condições institucionais (meso) e sociais (macro) que podem não ser as mais desejáveis e favoráveis, têm um significativo "espaço de manobra" no que se refere a aspetos tais como a organização e estruturação do ensino, a seleção de tarefas, o envolvimento e participação dos alunos e a natureza da avaliação utilizada. Assim, apresentam-se de seguida algumas conclusões e reflexões tendo em conta o quadro conceitual que se construiu a partir da síntese da literatura de Fernandes e Fialho (2012) e, naturalmente, as questões que orientaram a pesquisa.

Tal como já tinha sido ilustrado por Albertino e De Sousa (2004) e por Klenowski et al. (2006), esta pesquisa mostrou que foi possível organizar e estruturar o ensino utilizando uma diversidade de tarefas a partir das quais os alunos puderam aprender e que facilitaram a integração dos processos de ensino, aprendizagem e avaliação. As dinâmicas criadas na sala de aula, com elevado empenho, participação e autonomia dos alunos, pareceram estar fortemente relacionadas com a natureza e variedade de tarefas, com a "proximidade" do docente e com a clareza da estrutura das aulas. Foi possível verificar, do mesmo modo que Berg et al. (2006) e Bloxham e West (2004), que a participação 
dos alunos nos processos de avaliação, nomeadamente através da auto e da heteroavaliação, contribui para que se concentrem melhor no que é necessário aprender, melhorando os seus níveis de atenção e de motivação. Os momentos de análise e reflexão sobre o trabalho realizado, que funcionam como momentos de balanço, foram muito valorizados pelos alunos que os associaram à melhoria das suas aprendizagens e à clarificação do que era necessário fazer, tal como, aliás, as pesquisas de Nicol (2009) e Taras (2002) também tinham evidenciado.

A distribuição de feedback, imediatamente ou pouco tempo após a realização de uma tarefa, revelou ser um procedimento muito valorizado pelos alunos porque, na sua opinião, os ajudava a orientar e/ou reorientar o seu trabalho, tornando claro o que se pretendia, a situação em que se encontravam e o caminho que tinham que percorrer para alcançar os objetivos de aprendizagem. Verificou-se, do mesmo modo que Carless (2002), Trotter (2006) e Mok et al. (2006) já tinham sugerido nas suas pesquisas, que, em geral, o feedback era de natureza criterial, sendo utilizado para ajudar os alunos a aprender, para formular juízos acerca do seu trabalho e para atribuir classificações.

Em suma, independentemente de outras conclusões que podem ser inferidas do trabalho empírico que aqui se apresentou e discutiu, interessa sublinhar que, através desta pesquisa, foi identificado um conjunto de características que, de acordo com o conhecimento existente, está relacionado com melhores e mais profundas aprendizagens por parte dos alunos. Indicam-se a título de exemplo, aspetos tais como: a) aulas estruturadas com propósitos claros e bem definidos; b) dinâmicas de ensino e avaliação diversificadas, baseadas na utilização de uma variedade de tarefas criteriosamente selecionadas; c) estratégias que suscitem o envolvimento e a participação ativa dos alunos nos processos de aprendizagem e avaliação; d) distribuição sistemática e atempada de feedback de qualidade com propósitos diferenciados; e) utilização da avaliação formativa como forma de apoiar o desenvolvimento das aprendizagens dos alunos; f) realização de momentos de análise e reflexão que induzam a utilização de processos de auto e heteroavaliação e o desenvolvimento das competências metacognitivas dos alunos.

\section{REFERÊNCIAS}

ALBERTINO, F.; DE SOUSA, N. Avaliação da aprendizagem: o portfólio como auxiliar na construção de um profissional reflexivo. Estudos em Avaliação Educacional, São Paulo, n. 29, p. 169-189, jan./jun. 2004. 
ANDRADE, H.; DU, Y. Student responses to criteria-referenced self-assessment. Assessment and Evaluation in Higher Education, New York, NY, v. 31, n. 3, p. 341-356, 2007.

BALLANTYNE, R.; HUGHES, K.; MYLONAS, A. Developing procedures for implementing peer assessment in large classes using an action research process. Assessment and Evaluation in Higher Education, New York, NY, v. 27, n. 5, p. 427-441, 2002.

BERG, I.; ADMIRAAL, W.; PILOT, A. Design principles and outcomes of peer assessment in higher education. Studies in Higher Education, London, v. 31, n. 3, p. 341-356, 2006.

BIGGS, G. How assessment frames student learning. In: BRYAN, C.; CLEGG, K. (Orgs.). Innovative Assessment in Higher Education. New York: Taylor and Francis Group, 2006. p. 23-36.

BLACK, P.; WILIAM, D. Assessment and classroom learning. Assessment in Education: principles, policy \& practice, London, v. 5, n. 1, p. 7-74, 1998.

BLACK, P.; WILIAM, D. Assessment for learning in the classroom. In: GARDNER, J. (Ed.). Assessment and learning. London: Sage, 2006. p. 9-25.

BLOXHAM, S.; WEST, A. Understanding the rules of the game: marking peer assessment as a medium for developing students' conceptions of assessment. Assessment and Evaluation in Higher Education, New York, NY, v. 29, n. 6, p. 721-732, 2004.

BOUD, D. Sustainable assessment: rethinking assessment for the learning society. Studies in Continuing Education, London, v. 22, n. 2, p. 151-167, 2000.

BRYAN, C.; CLEGG, K. Innovative Assessment in Higher Education. New York: Taylor and Francis Group, 2006. Introdução, p. 3-10.

CARLESS, D. R. The 'Mini-Viva' as a tool to enhance assessment for learning. Assessment and Evaluation in Higher Education, New York, NY, v. 27, n. 4, p. 354-363, 2002.

COOK, A. Assessing the use of flexible assessment. Assessment and Evaluation in Higher Education, New York, NY, v. 26, n. 6, p. 539-549, 2001.

DANCER, D.; KAMVOUNIAS, P. Student involvement in assessment: A project designed to assess class participation fairly and reliably. Assessment and Evaluation in Higher Education, New York, NY, v. 30, n. 4, p. 445-454, 2005.

ERICKSON, F. Qualitative methods in research on teaching. In: WITTROCK, M. (Ed.). Handbook of research on teaching. New York: MacMillan, 1986. p. 119-161.

ESCUDERO, J. M. Claros y oscuros del Espacio Europeo de Educación Superior como innovación educativa. In: LEITE, C.; ZABALZA, M. (Coords.). Ensino superior: inovação e qualidade na docência. Porto: Centro de Investigação e Intervenção Educativas da Faculdade de Psicologia e de Ciências da Educação da Universidade do Porto, 2012. p. 5-34.

FALCHIKOV, N. Improving assessment through student involvement: practical solutions for aiding learning in higher and further education. New York: Routledge Farmer, 2005. 
FERNANDES, D. Avaliar para aprender: fundamentos, práticas e políticas. São Paulo: Editora Unesp, 2008.

FERNANDES, D.; FIALHO, N. Dez anos de práticas de avaliação das aprendizagens no Ensino Superior: uma síntese da literatura (2000-2009). In: LEITE, C.; ZABALZA, M. (Coords.). Ensino superior: inovação e qualidade na docência. Porto: Centro de Investigação e Intervenção Educativas da Faculdade de Psicologia e de Ciências da Educação da Universidade do Porto, 2012. p. 3693-3707.

GALE, K.; MARTIN, K.; MCQUEEN, G. Triadic assessment. Assessment and Evaluation in Higher Education, New York, NY, v. 27, n. 6, p. 557-567, 2002.

GARDNER, J. (Ed.). Assessment and learning. London: Sage, 2006.

GIBELS, D.; SEGERS, M.; STRUYFUL, E. Constructivist learning environments and the (im)possibility to change students' perceptions of assessment demands and approaches to learning. Instructional Science: An International Journal of the Learning Sciences, New York, v. 36, n. 5-6, p. 431-443, 2008.

JOHNSTON, L.; MILES, L. Assessing contributions to group assignments. Assessment and Evaluation in Higher Education, New York, NY, v. 29, n. 6, p. 751-768, 2004.

KLENOWSKI, V.; ASKEW, S.; CARNELL, E. Portfolios for learning, assessment and professional development in higher education. Assessment and Evaluation in Higher Education, New York, NY, v. 31, n. 3, p. 267-286, 2006.

MACMILLAN, J.; MCLEAN, M. Making first-year tutorials count: operationalizing the assessment-learning connection. Active Learning in Higher Education, London, v. 6, n. 2, p. 94-105, 2005.

MERRIAM, B. Case study research in education: A qualitative approach. San Francisco: Jossey-Bass Publishers, 1988.

MILLER, T. Formative computer-based assessment in higher education: the effectiveness of feedback in supporting student learning. Assessment and Evaluation in Higher Education, New York, NY, v. 34, n. 2, p. 181-192, 2009.

MOK, M. et al. Self-assessment in higher education: experience in using a metacognitive approach in five case studies. Assessment and Evaluation in Higher Education, New York, NY, v. 31, n. 4, p. 415-433, 2006.

NICOL, D. Assessment for learner self evaluation: enhancing achievement in first year using learning technologies. Assessment and Evaluation in Higher Education, New York, NY, v. 34, n. 3, p. 335-352, 2009.

ORSMOND, P.; MERRY, S.; REILING, K. The use of exemplars and formative feedback when using student derived marking criteria in peer and self-assessment. Assessment and Evaluation in Higher Education, New York, NY, v. 27, n. 4, p. 309-323, 2002. 
POON, W. et al. Improving assessment methods in university science education with negotiated self - and peer - assessment. Assessment and Evaluation in Higher Education, New York, NY, v. 16, n. 3, p. 331-346, 2009.

PRICE, M.; O'DONOVAN, B. Improving performance trough enhancing student understanding of criteria and feedback. In: BRYAN, C.; CLEGG, K. (Orgs.). Innovative Assessment in Higher Education. New York: Taylor and Francis Group, 2006. p. 100-109.

TARAS, M. Using assessment for learning and learning from assessment. Assessment and Evaluation in Higher Education, New York, NY, v. 27, n. 6, p. 501-510, 2002.

TROTTER, E. Student perceptions of continuous summative assessment. Assessment and Evaluation in Higher Education, New York, NY, v. 31, n. 5, p. 505-521, 2006.

WALKER, M.; WARHURST, C. In most classes you sit around very quietly at a table and get lectured at...' debates, assessment and student learning. Teaching in Higher Education, London, v. 1, n. 1, p. 33-49, 2000.

WANOUS, M.; PROCTER, B.; MUSHIDB, K. Assessment for learner self evaluation: enhancing achievement in first year using learning technologies. European Journal of Engineering Education, London, v. 34, n. 1, p. 77-85, 2009.

WOLCOTT, H. Transforming qualitative data: description, analysis, and interpretation. London: Sage, 1994.

YORKE, M. Formative assessment in higher education: moves towards theory and the enhancement of pedagogic practice. Higher Education, Berlim, v. 45, n. 4, p. 477-501, 2003.

Texto recebido em 22 de maio de 2015. Texto aprovado em 04 de agosto de 2015. 
